\title{
OS BEBÊS E AS APRENDIZAGENS: UMA PROPOSTA DE INTERVENÇÃO FORMATIVA
}

\author{
Cassiana Magalhães \\ magalhaes.cassiana@gmail.com \\ Universidade Estadual de Londrina \\ Lucineia Maria Lazaretti \\ lucylazaretti@gmail.com \\ Universidade Estadual de Maringá \\ Nádia Mara Eidt \\ nadiaeidt@hotmail.com \\ Universidade Estadual de Londrina
}

RESUMO: O presente trabalho visa apresentar as contribuições da Psicologia HistóricoCultural para organizar o trabalho educativo com bebês, usando como recurso o cesto de tesouros. Entendemos que recursos dessa natureza podem auxiliar na organização do trabalho pedagógico com bebês contribuindo para a aprendizagem e desenvolvimento de capacidades psíquicas dos pequeninos. A possibilidade de intervenção que deu origem a esse trabalho foi realizada no berçário de uma instituição municipal do interior do Paraná, mediante parceria entre a coordenadora do PIBID, supervisora (a professora do berçário) e alunos bolsistas do Programa. Como resultados, consideramos que o trabalho educativo, quando planejado com recursos mediadores, amplia as possibilidades de interesses e de aprendizagens dos bebês.

PALAVRAS-CHAVE: bebês, intervenção pedagógica, psicologia histórico-cultural.

\section{BABIES AND LEARNING: A TRAINING INTERVENTION PROPOSAL}

ABSTRACT: This paper presents the contributions of Historical-Cultural Psychology to organize educational work with babies, using the basket of treasures as resource. We believe that such resources can assist in the organization of the pedagogical work with babies helping them in learning and developing psychic abilities. The possibility of intervention that gave rise to this work was carried out in a nursery class in a municipal institution in the interior of Paraná, through a partnership between the coordinator of PIBID, its supervisor (nursery teacher) and its scholarship students. As a result, we believe that the educational work, as planned with mediators resources, expands the possibilities of interests and learning of babies.

KEYW ORDS: babies, pedagogical intervention, historical-cultural psychology. 


\section{Introdução}

A prática pedagógica com os bebês, especificamente durante o primeiro ano de vida, encerra muitos desafios. Isso pode ser comprovado pelas inúmeras pesquisas que atestam persistir ações restritas às necessidades básicas de sono, alimentação e higiene, sem o olhar atento às outras possibilidades educativas que possam contribuir nas conquistas de aprendizagem e desenvolvimento dos pequeninos (LAZARETTI, 2013; BARBOSA, 2000).

Temos nos deparado com espaços de berçários repletos de berços, paredes coloridas e enfeitadas, porém, pouco promotores do desenvolvimento dos bebês. Professores que se comunicam entre eles, mas não se comunicam com as crianças pequenas. Espaços externos pouco ou nada utilizados, chão pouco experimentado. No discurso de parte dos professores responsáveis por esse segmento, é possível encontrar a dificuldade de se trabalhar com bebês. As atividades propostas ainda se centram, em grande medida, a "carimbos" de mãos, pés e dedos.

Essa constatação revela qual é a concepção de criança e de desenvolvimento que ainda reina em boa parte do discurso e das práticas docentes. Persiste a ideia do não-domínio, do não-saber dos bebês e que eles ainda não têm determinadas capacidades e habilidades e, por isso, inviabiliza qualquer ação educativa, persistindo a pedagogia da espera.

Diante disso, esse texto objetiva apresentar as contribuições da Psicologia HistóricoCultural na compreensão da aprendizagem e do desenvolvimento da criança, relatando possibilidades de intervenção com os bebês na direção de ampliar e diversificar a relação criança-mundo. Essa possibilidade de intervenção foi concretizada no berçário de uma instituição municipal do interior do Paraná, que atende crianças de 4 meses a 1 ano e 6 meses de idade, mediante parceria entre a coordenadora do PIBID $^{1}$, supervisora (a professora da turma) e alunos bolsistas do Programa. Tal parceria ocorreu durante o ano de 2014, mediada pelo estudo e análise da relação entre ensino, aprendizagem e desenvolvimento à luz da Teoria Histórico-Cultural, pela intencionalidade do trabalho do professor junto aos bebês e pela confecção de um cesto de tesouros como recurso para promover o desenvolvimento de novas necessidades e capacidades psíquicas nos bebês.

\footnotetext{
${ }^{1}$ Programa Institucional de Bolsa de Iniciação à Docência.
} 


\section{O Cesto de Tesouros: uma proposta de intervenção formativa e o primeiro ano de vida da criança}

O primeiro ano de vida é marcado pela relação emocional e afetiva que a criança estabelece com o adulto. As ações de cuidado e de atenção provocam comunicação e medeiam a relação bebê-adulto pela atividade conjunta que origina aprendizagens cada vez mais complexas. A característica fundamental do "[...] recém-nascido é a sua capacidade ilimitada para assimilar novas experiências e adquirir as formas de comportamento que caracterizam o homem” (MUKHINA, 1996, p. 76). Desde os primeiros meses, é intensa a relação do bebê com o adulto e também com a realidade circundante, e essa relação reorganiza o desenvolvimento do bebê, em que, num primeiro momento, predominam necessidades biológicas e orgânicas e, progressivamente, surgem necessidades sociais. Desse modo, o desenvolvimento psíquico da criança começa a se formar no processo de educação, efetivado pelos adultos, que, além de satisfazerem as necessidades imediatas da criança, organizam sua vida e criam condições para que seja formada a experiência social (ELKONIN, 1969).

Essa experiência social é formada pela atividade conjunta com os adultos e potencializa conquistas no desenvolvimento do bebê durante o primeiro ano. $\mathrm{O}$ adulto comunica-se com o bebê que, como consequência, forma as premissas da linguagem por meio dos primeiros balbucios e sons.

Além disso, nessa comunicação origina-se a necessidade de deslocar-se, de mover-se, de rolar, de arrastar-se. Com isso, amplia-se o conjunto de objetos que pode alcançar, os quais, por isso, convertem-se em objetos de seu conhecimento, revelando suas propriedades. Significa que desde os mais simples movimentos, quando o adulto se inclina sobre a criança, aproxima e afasta seu rosto, pega, mostra e estende a ela algum objeto de cor viva, ensejam um motivo para que a criança fixe seu olhar no rosto do adulto ou no objeto. Esses primeiros movimentos, até a conquista de segurar e apalpar o objeto, estão voltados para um intenso desenvolvimento e com inúmeras possibilidades de relação entre a criança e o adulto e favorecem o desenvolvimento de funções psíquicas como a sensação, a percepção, a atenção e a memória. A promoção do desenvolvimento da sensação e da percepção é um dos principais objetivos do trabalho docente no primeiro ano de vida: 
Um dos focos do trabalho educativo nos primeiros meses de vida é, pois, a organização intencional de situações educativas que possibilitem à criança perceber cores, sons, texturas, cheiros, sabores, resultante da relação comunicativa do(a) professor(a) como bebê. Nessa relação, esse profissional propõe oportunidades educativas capazes de garantiro direito dos bebês a ricas experiências olfativas, gustativas, auditivas, visuais e táteis, dirigindo-se carinhosamente e falando diretamente com eles, enaltecendo o barulho e o cheiro da chuva, por exemplo, ou lhe instigando a saborear uma fruta (LIMA, VALIENGO e RIBEIRO, 2014, p. 28-29).

Por meio da intervenção pedagógica, ampliam-se as possibilidades de manipulação, durante o primeiro ano, formando novas capacidades, como por exemplo, concentrar-se, examinar, apalpar, ouvir, entre outras, e, com a formação do ato de agarrar, a atividade orientadora e a exploradora adquirem uma nova configuração quando a criança começa a se orientar pelos novos objetos. As ações da criança "[...] são estimuladas pela novidade dos objetos e sustentadas pelas novas qualidades dos objetos que vão sendo descobertas durante a sua manipulação" (ELKONIN, 1998, p. 214).

Vale ressaltar que, de acordo com Martins (2009, p. 105), a mediação intencional do adulto é essencial para a transformação da atenção involuntária para a voluntária. "A possibilidade de manejar as coisas amplia seu círculo de atenção, permitindo o treino de focalização e fixação a uma vasta gama de estímulos visuais, auditivos, táteis, etc." Ainda de acordo com a mesma autora, a expressão mais primitiva da memória do bebê é o reconhecimento das pessoas e objetos à sua volta. Com o desenvolvimento da linguagem verbal, há um considerável enriquecimento desses registros.

Tendo em vista a criação de novas necessidades no bebê e o desenvolvimento de suas funções psíquicas, uma proposta alternativa para o trabalho pedagógico com esse segmento é o cesto de tesouros, que contém um aglomerado de objetos de diferentes texturas, cores, tamanhos, cheiros, preferencialmente oriundos de materiais naturais e de outros objetos de uso cotidiano do adulto que geralmente estão fora do alcance das crianças (GOLDSCHMIED; JACKSON, 2006). De acordo com o manual de orientação pedagógica organizado pelo Ministério da Educação (BRASIL, 2012), a organização do cesto inicia-se com uma pesquisa na comunidade para conhecer os objetos de uso do cotidiano. O segundo momento é o de escolha de materiais com diferentes características e propriedades: duros, moles, ásperos, macios e outros. O próximo passo é verificar se os objetos estão limpos e são seguros. Finalmente, colocá-los em uma cesta de vime, firme, sem alças e sem farpas. O manual organiza ainda uma lista com sugestões de materiais, separando-os em: objetos da natureza, objetos feitos com materiais naturais ou outros 
materiais de uso cotidiano, objetos de madeira, objetos de metal, objetos de couro, têxteis, borracha e pele, objetos de papel e papelão. Orienta-se, ainda, acrescentar materiais que representem as práticas culturais de cada comunidade (BRASIL, 2012).

Majem e Òdena (2010) sugerem que o interessante é reunir sessenta objetos organizados de modo atrativo em um cesto firme com aproximadamente trinta e cinco centímetros de diâmetro e oito centímetros de altura. Além da higienização dos objetos, cabe ressaltar a necessidade de substituí-los, criando assim, novos interesses e proporcionando descobertas. As autoras (2010) afirmam ainda que, mesmo sem a interferência do adulto, este é para as crianças um ponto de referência. "[...] É importante que observe as transformações e os progressos de cada criança, e que perceba quais objetos querem alcançar e quais meios utilizam para isto" (MAJEM e ÒDENA, 2010, p.27).

Além disso, à luz dos pressupostos da Psicologia Histórico-Cultural, ressaltamos que o adulto está envolvido na organização do cesto, na seleção dos materiais, na organização do tempo que destina à exploração e tateio, como também, na observação das ações dos bebês, na promoção de iniciativas para exploração e no respeito aos limites que eles apresentam. Entendemos que o adulto assume papel central na medida em que promove o ensino da linguagem verbal junto às crianças, evidenciando o nome dos objetos e suas respectivas funções sociais.

\section{A proposta de intervenção: metodologia, resultados e discussões}

Com base nos pressupostos teóricos da Psicologia Histórico-Cultural, organizamos, juntamente com as alunas e uma supervisora do PIBID, uma atividade de intervenção no berçário de uma instituição municipal do interior do Paraná, utilizando como recurso o cesto de tesouros. As alunas permaneceram na turma de uma das supervisoras do PIBID que atende crianças de 4 meses a 1 ano e 6 meses de idade, durante o período de um ano. O período de permanência das crianças na instituição é de aproximadamente 11 horas, sendo que duas professoras assumem a turma no período da manhã e outras duas no período da tarde, todas concursadas pela Prefeitura Municipal e com curso superior. Durante o período de observação, verificou-se que muitas das ações das professoras eram dirigidas à rotina, porém a professora da turma e supervisora do 
PIBID enfatizou a importância de se fazer o planejamento e organizar o espaço de modo a promover o desenvolvimento das crianças.

Tendo isso em vista, inicialmente, foi realizado um grupo de estudos envolvendo a coordenadora do PIBID, a supervisora (a professora da turma) e alunas bolsistas do Programa, visando a construção do cesto de tesouros e o estudo e discussão teórica sobre: 1) a relação entre ensino, aprendizagem e desenvolvimento à luz da Psicologia HistóricoCultural, 2) a intencionalidade do trabalho do professor junto aos bebês e 3) O cesto de tesouros como recurso para promover o desenvolvimento de novas necessidades e capacidades psíquicas nos bebês. Foi discutido que a orientação de Goldschmied e Jackson (2006) era para deixar os bebês explorarem livremente os objetos que integram o cesto, dando menor importância à intervenção do adulto nesse primeiro momento. Adotando o referencial da Psicologia Histórico-Cultural, pensou-se em uma maneira de ampliar ainda mais as possibilidades de exploração do cesto com o objetivo de criar novas necessidades nos bebês. Como procuraremos mostrar a seguir, o professor assume um papel fundamental, favorecendo mediações que permitam que a criança comece a compreender a função social dos objetos e suas qualidades no interior da prática social humana. Ao assim fazer, por um lado, o educador promove o desenvolvimento de funções psíquicas $^{2}$ como a atenção, a memória, a linguagem e as operações lógicas do pensamento, quais sejam, análise, síntese e generalização. Por outro, ele engendra a criação das bases para a formação de novos interesses, como a manipulação de objetos, a brincadeira de faz-de-conta, a imitação, fazendo com que o desenvolvimento infantil avance. Tendo isso em vista, foi organizado um cesto com diversos materiais e também pensado em maneiras de organizar o espaço com desafios e objetos interessantes para manipulação. Assim, toda semana tinha uma novidade: uma rede com utensîlios de cozinha pendurados, desafios embaixo de uma bancada, berços virados com coisas dentro e muito mais. Neste texto, trazemos a proposta de intervenção com o cesto de tesouros e as cenas que demonstram o que discutimos e que aconteceram no ano de 2014.

\footnotetext{
${ }^{2}$ Pasqualinie Mesquita (2008) definemfunção psíquica como sendo uma propriedade de ação de que dispõe nos so psiquis mo no proces so de captação da realidade objetiva. Constituemfunções psíquicas (ou processos funcionais): sensação, percepção, memória, linguagem, pensamento, imaginação, emoção e sentimentos .
} 


\section{Cena 1: "Explorando a barriga"}
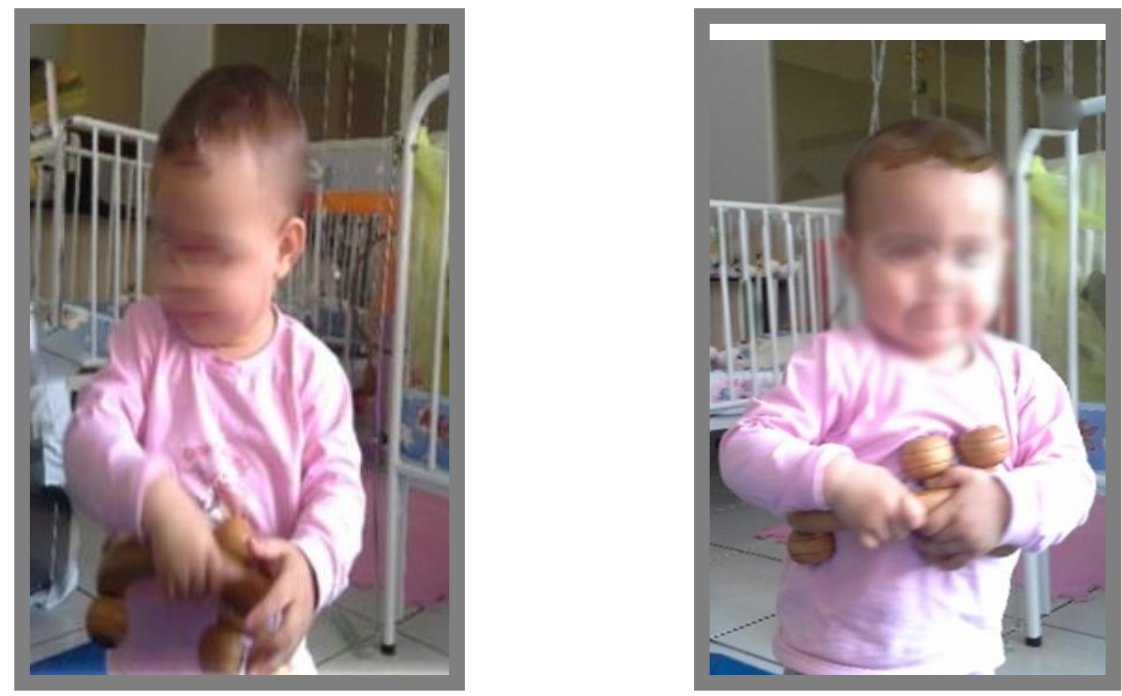

Fonte: arquivo da pesquisadora (2014)

Nessa cena, a partir do cesto de tesouros formado por diferentes utensílios de madeira, os bebês estavam manipulando objetos indistintamente, se familiarizando com as suas diferentes propriedades: formas, tamanhos, peso. $\mathrm{Na}$ atividade conjunta com a professora, que orienta uma maneira de manipular o objeto, criando assim, uma nova necessidade e despertando uma atitude na criança, que imita a ação do adulto. Um objeto utilizado indiscriminadamente, a partir da mediação da professora, agora serve para massagear a barriga. Durante a observação evidenciamos que, quando a professora diz: "faz massagem na barriga", a criança compreende a frase, pega o objeto e faz "massagem" no lugar do corpo indicado pela professora. Nessa cena, duas importantes observações servem de premissas para orientar o fazer docente: o papel da imitação e a linguagem oral. O professor, na atividade conjunta, foi um modelo de ação, que produziu uma ação adequada com o objeto e a criança reproduziu e imitou, com ações reiterativas e concatenadas.

O professor, os adultos mais próximos, são sempre modelos de ação na qual portam a experiência social e as quais a criança irá imitar e se apropriar dessas ações que constituirão sua experiência individual. É pela imitação e observação, como prática cotidiana, das relações estabelecidas com os pares, em ambiente escolar e/ou ou familiar, que a criança amplia ações e manifesta um crescente interesse em manipular os objetos cotidianos, como cadeira, chapéu ou um lenço. Esses novos interesses demonstram uma transição nos motivos das crianças, em que o adulto deixa de ser o centro da situação 
social de desenvolvimento e o conteúdo de principal interesse das crianças passa a ser manipular objetos e se apropriar de novas e aprimoradas ações com eles. Leontiev (1969, p. 346) explica que são os motivos que estimulam a ação, e esta é dependente do sentido que tenha para a criança: "Se denomina motivo da atividade aquilo que, refletindo-se no cérebro do homem, excita a atuar e dirigir esta ação a satisfazer uma necessidade determinada". A complexificação da atividade produz novas necessidades, novos motivos e, com isso, ocorre a transição da atividade da criança. É na esteira dessa relação criançaadulto que a criança começa a compreender a utilização dos objetos cotidianos ao mesmo tempo em que se apropria de regras do comportamento social. Nesse processo de aprendizagem, domina as ações com orientação constante do adulto, que lhe demonstra a ação, dirige sua mão e chama atenção sobre o resultado (MUKHINA, 1996). Se houver mediações intencionais, um ensino organizado em que o professor desempenhe sua função de ensinar, a criança poderá aprender a manipular e atuar com os objetos cotidianos por meio dos quais satisfaz suas variadas necessidades (comer com a colher, beber com a xícara, abotoar os botões, colocar as meias, etc.), isso produzirá na criança habilidades, capacidades e hábitos que enriquecerão seu desenvolvimento psíquico (ELKONIN, 1969).

Em relação à linguagem, à comunicação, à nomeação, ao uso e funções dos objetos, origina ampliação, riqueza e diversidade na linguagem oral da criança, ao conseguir reconhecer e pegar objetos nominados, bem como, posteriormente, farão parte do repertório de vocabulário da criança. $\mathrm{O}$ adulto pode neste momento intensificar a comunicação com a criança questionando: "onde está tal objeto?", "vamos pentear o cabelo?" e assim por diante. Venguer (1986, p.117) salienta que “[...] a principal atividade nas crianças da primeira infância está relacionada com a percepção dos sons. Por esta razão desenvolve-se de forma intensa o ouvido fonemático (responsável pela discriminação dos sons), a percepção dos sons da língua materna”.

De acordo com Venger (1976, p. 122), uma das principais funções da linguagem é a comunicação: "[...] a comunicação surge motivada pela situação concreta, dentro da qual estão incluídos os adultos e a criança". Pela ampliação da comunicação no círculo de vivências da criança, exige-se dela um domínio cada vez mais elaborado dos meios comunicativos, e o principal deles é a fala. A fala, como estímulo auxiliar, além de ser um meio de contato social com as pessoas do entorno social, desempenha uma função específica na organização da conduta da criança: 
As palavras dirigidas à solução de um problema não somente referem-se aos objetos pertencentes ao mundo exterior, mas alcançam também o próprio comportamento da criança, as suas ações e intenções. Por meio da fala, a criança demonstra ser capaz, pela primeira vez, de dominar sua própria conduta e de relacionar-se consigo mesmo externamente, considerando-se a si mesma como um certo objeto. A fala ajuda a criança a dominar esse especial objeto por meio da organização preliminar e do planejamento de seus próprios atos de conduta. Aqueles objetos que se encontravam além do alcance de suas operações práticas se fazem agora, graças à fala, acessíveis na atividade da criança (VYGOTSKI; LURIA, 2007, p. 24, tradução nossa).

A cena observada dispõe de elementos importantes para reflexão sobre a organização do ensino com os bebês: o olhar atento do professor ao observar as crianças e suas manifestações e, com isso, intervir adequadamente com falas, gestos e objetos que potencializam a experiência da criança e amplia o repertório de conhecimentos sobre a realidade.

\section{Cena 2: "Limpando o nariz"}

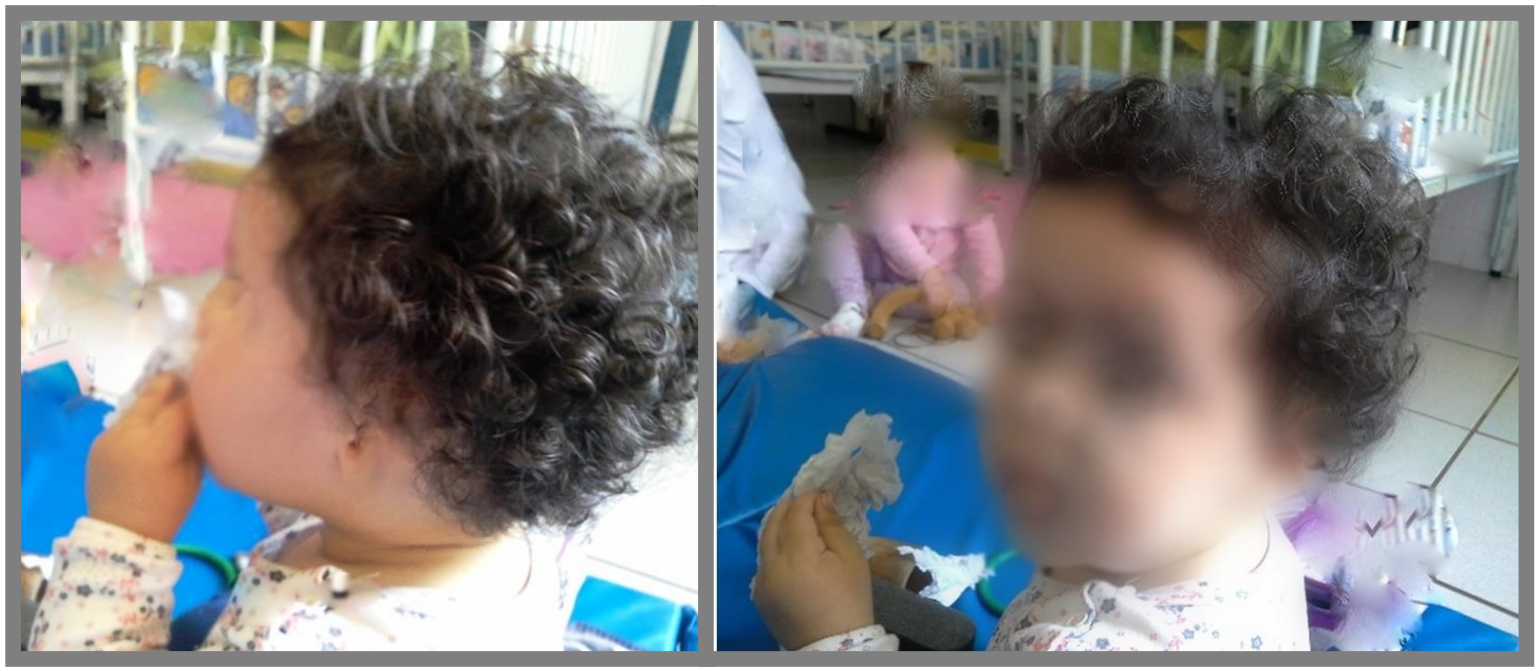

Fonte: arquivo da pesquisadora (2014)

Nessa segunda cena selecionada, o cesto de tesouros estava organizado com materiais diversos, entre eles papéis de diferentes espessuras, tal como papel higiênico. A criança manipula papéis e amassa. Ao pegar o papel higiênico a professora diz: "vamos limpar o nariz?”. E a criança, primeiro, observa ao redor, as demais crianças estão explorando outros materiais do cesto, duas professoras estão sentadas no chão, próximas às crianças, em seguida, vira-se para a professora e realiza a ação. 
Nessa cena, a relação com o objeto - o papel - adquire uma função social, mediada pela orientação verbal da professora. O papel, além de poder ser amassado e manipulado, enquanto ações primárias, adquire uma função no seu uso social. Ao limpar seu nariz, provavelmente, a criança não executou com maestria tal ação, porém, três importantes observações podem ser efetuadas: a orientação verbal, o domínio sensório-motor e a função social dos objetos. Aprender a manusear adequadamente os objetos cotidianos, como colher, lápis, entre outros, demandam constantes ações de manipulação repetitivas que ocorrem diariamente. Significa que, nas situações pedagógicas, quanto mais rico e diverso for o acesso a objetos a serem conhecidos, manipulados, explorados e executados, maior será a experiência de ação da criança. Concomitantemente, essas ações com os objetos, mediados pelos adultos, progressivamente engendram uma nova forma de atitude diante do mundo dos objetos: estes se tornam não mais simples objetos apalpados, mas instrumentos que têm uma forma determinada para seu uso - um domínio dos seus procedimentos -, socialmente elaborado, e é necessário aprender a cumprir a função que lhes designou a experiência social. A criança aprende por meio da influência educativa e formativa dos adultos, o significado social dos objetos, fixados pela atividade humana, e as propriedades funcionais dos objetos, orientando-se a buscar em cada novo objetoinstrumento seu destino específico. O domínio das ações com os objetos, com instrumentos culturais, mediatiza a relação da criança com o mundo objetivo e são fundamentais no desenvolvimento do psiquismo da criança.

\footnotetext{
Observando as ações dos adultos com os objetos, o pequeno se apropria das formas humanas da atividade prática objetivada. Na ação com os objetos, a criança descobre que muitos deles podem ser utilizados de modo similar. Este tipo de descoberta conduz à generalização não somente dos objetos similares (por alguma característica), como também a generalizar a experiência da atividade (MÚJINA, 1979, p. 54, tradução nossa).
}

Nas duas cenas, podemos constatar o importante papel da professora. Na medida em que disponibiliza os objetos também interfere na ação com os mesmos. Para Mukhina (1996, p.51), “[...] o papel diretivo do ensino no desenvolvimento psíquico da criança manifesta-se no fato de que a criança assimila novas ações, inicialmente orientada e ajudada pelo adulto, depois sozinha". As ações da professora podem tanto apresentar os objetos para os bebês, como ampliar suas necessidades em relação à linguagem. $O$ que pretendemos é evidenciar que a exploração do cesto com a intervenção do adulto pode ser mais rica e qualificada do que a simples manipulação dos objetos pela criança. 
De acordo com Venguer (1986, p.116)

\begin{abstract}
Se os objetos estão simplesmente ante a visão da criança, inclusive se ela o examinar, mas não sentir necessidade de determinar especialmente sua forma, sua cor, as relações de tamanho ou outras propriedades, is so não determinará nela a formação de representações precisas. Tais representações, formar-se-ão somente como resultado da execução de ações de percepção, relacionados com os objetos que apresentem distintas propriedades. E essas ações, como já vimos, estão relacionadas com os tipos de atividade prática característicos da criança, fundamentalmente com a atividade com objetos. Por isso, a acumulação de representações sobre a propriedade dos objetos, dependerá da medida em que a criança considerar as diversas características (distintas formas, cores, relação de tamanho, etc.), durante suas ações com objetos, já tendo dominado a orientação visual ao orientar essas ações.
\end{abstract}

A afirmação justifica a necessidade de o professor organizar as ações de modo que, além da atuação dos bebês, é preciso nomear os objetos, ensinar seu uso e, assim, ampliar as relações com os objetos da cultura e com os motivos pelos quais foram criados. Isso porque compreendemos que o adulto, nesse processo, ocupa um lugar importante, já que é pela atividade conjunta entre crianças e adultos e criança-criança que ocorrem infinitas aprendizagens. $\mathrm{O}$ adulto não apenas disponibiliza e organiza, mas, como portador vivente da experiência social, apresenta e significa o mundo dos objetos humanos. Conforme Lísina (1987, p.286): “Agora a criança está absorta pelos objetos. Por exemplo: ela olha para o adulto que lhe dirige a palavra. $\mathrm{O}$ adulto the mostra um objeto e na criança imediatamente desperta um ávido interesse por ele". Nesse sentido, que o desenvolvimento da criança é sempre um processo de transformação, que, pela mediação do Outro, altera sua condição de ser biológico num ser cultural.

O processo de desenvolvimento se forma sob a influência das relações externas, sociais, que reconfiguram as funções elementares agregando características superiores, por meio de ações mediadas e intencionais. Essa ação sobre a realidade se complexifica pela mediação do adulto na atividade da criança. Nas palavras de Mukhina (1996, p.50): "Sem dúvida, é melhor um ensino não espontâneo, consciente, que dê à criança o que ela necessita e garanta seu pleno desenvolvimento". Assim, a criança se desenvolve assimilando a experiência social, por isso, a necessidade de aprender o comportamento do homem.

Diante disso, algumas premissas podem ser destacadas para o trabalho pedagógico com os bebês: a sensibilidade do professor em organizar os espaços e o tempo de modo a permitir que as crianças explorem, executem, imitem e ampliem sua experiência cultural; a riqueza, amplitude e variedade de instrumentos físicos engendrem novas necessidades 
de atuar e manipular os objetos que estão ao seu alcance; o professor executa o uso com esses objetos, manipula junto com a criança, demonstra o uso e permite que a criança também descubra novos usos com os objetos; a linguagem oral e gestual é o elemento central desse processo, por meio dela, os objetos, os recursos, os instrumentos físicos são significados pelo instrumento simbólico - a linguagem.

A linguagem é resultado da constante necessidade de comunicação entre a criança e o mundo, desde seus primeiros meses, a qual, pela atividade conjunta com os adultos, começa a compreender as relações existentes entre as palavras pronunciadas e a realidade concreta que expressam (MÚJINA, 1979). A linguagem, como um signo, é produto da atividade das gerações anteriores. A criança, no decurso de seu desenvolvimento, faz dela a sua língua, por meio da apropriação, formando nela funções e aptidões especificamente humanas (VENGER, 1976). É pela comunicação, inicialmente prática, que o desenvolvimento psíquico se realiza. Desde o início, pela comunicação verbal com os demais membros do meio circundante, a criança começa a elaborar palavras, a compreender sua significação e passa a utilizá-las ativamente na sua linguagem. Apropriar-se da linguagem é condição para que os processos psíquicos se desenvolvam, já que o conteúdo da experiência prática humana não se fixa apenas sob coisas materiais, mas, sobretudo, como conceito e reflexo na palavra. Os conceitos representam a riqueza do saber acumulado pela humanidade, e a criança, ao apropriar-se deles, apreende conhecimentos que formam funções e faculdades psíquicas próprias do homem como ser social. É por isso que essa comunicação deve ser enriquecida e aprimorada, com o objetivo de conduzir a formação da fala, de promover articulação com palavras, o que provoca na criança uma reorganização radical nas funções psicológicas. É pelo domínio da linguagem que outras funções psíquicas se reestruturam nesse processo de aprendizagem, mediadas pelas ações e relações com a realidade circundante. A percepção da criança começa a se separar e diferenciar elementos, superando a estrutura natural do marco sensorial, desenvolvendo-se pela introdução de meios auxiliares de estímulos como a fala. "A fala não acompanha simplesmente a percepção infantil, mas desempenha nela, desde o início, um papel ativo. E assim a criança começa a perceber o mundo não somente por meio de seus olhos, mas também através da fala" (VYGOTSKI; LURIA, 2007, p. 38, tradução nossa).

Essas conquistas possibilitam o desenvolvimento de funções primárias, como a percepção visual, que adquire ações intencionais na manipulação dos objetos, em que, 
por meio da imitação, as crianças repetem várias vezes as ações que o adulto realiza. Essas ações intencionais e a imitação possibilitam manifestações elementares do pensamento infantil: "[...] na manipulação objetal surgem e se resolvem situações problemáticas elementares. Por conseguinte, a criança aprende a pensar nas ações, imitando seus próprios movimentos e também os alheios" (MUKHINA, 1979, p. 49, tradução nossa). A criança aprende, por meio da influência educativa e formativa dos adultos, o significado social dos objetos, fixados pela atividade humana, e as propriedades funcionais dos objetos, orientando-se a buscar em cada novo objeto-instrumento seu destino específico. Os objetos, como instrumentos culturais, mediatizam a relação da criança com o mundo objetivo.

$\mathrm{O}$ pensamento e a linguagem, como processos psíquicos, desenvolvem-se na experiência sensorial pelas ações instrumentais e pela influência do adulto que ensina à criança os modos de ação e denominação dos objetos. O pensamento se ativa em meio a situações de tarefas objetivas, em que a criança procura soluções intelectuais orientandose pelo adulto. Observando as ações dos adultos com os objetos, o pequeno se apropria das formas humanas da atividade prática objetivada. $\mathrm{Na}$ ação com os objetos, a criança descobre que muitos deles podem ser utilizados de modo similar. Este tipo de descoberta conduz à generalização não somente dos objetos similares (por alguma característica), como também a generalizar a experiência da atividade (MÚJINA, 1979).

\begin{abstract}
Sob a direção dos adultos e em constante contato com eles, a criança aprende a atuar comos objetos, por meio dos quais satisfazsuas variadas necessidades (comer com a colher, beber com a xícara, abotoar os botões, colocar as meias etc.). No começo, os adultos executam as ações junto com a criança e somente de uma maneira progressiva a deixam com liberdade, vigiando e corrigindo constantemente seus movimentos. Quando a organização e o método de ensino são bons, a criança aprende com perfeição as maneiras corretas de atuar com os objetos (ELKONIN, 1969, p. 508, tradução nossa).
\end{abstract}

Durante as distintas aprendizagens da criança, apropriando-se das formas humanas da atividade prática objetivada, ocorrem mudanças qualitativas no pensamento, como também vai aperfeiçoando o domínio da linguagem. A linguagem é resultado da constante necessidade de comunicação entre a criança e o mundo, desde seus primeiros anos, a qual, pela atividade conjunta com os adultos, começa a compreender as relações existentes entre as palavras pronunciadas e a realidade concreta que expressam. A linguagem, como um signo, é produto da atividade das gerações anteriores. A criança, no decurso de seu desenvolvimento, faz dela a sua língua, por meio da apropriação, 
formando nela funções e aptidões especificamente humanas (MÚJINA, 1979; VENGER, 1976).

\section{Considerações finais}

No decorrer deste texto, objetivamos apresentar as contribuições da Psicologia Histórico-Cultural para organizar o trabalho educativo com bebês, usando como recurso o cesto de tesouros. Percebemos a importância da utilização de recursos, brinquedos e ambientes que precisam ser enriquecidos e constantemente reorganizados, para que não se tornem enfadonhos e rotineiros no processo de atividade da criança. Por isso, o professor, ao organizar diferentes ambientes e espaços, cria situações novas, oferece elementos ainda desconhecidos, provocando a curiosidade e o interesse em manipular e agir em relação às possibilidades inovadoras.

\footnotetext{
O novo não só estimula a atividade da criança a respeito do objeto, mas também lhe proporciona apoio. As ações da criança de um ano são estimuladas pela novidade dos objetos e sustentadas pelas novas qualidades dos objetosque vão sendo descobertas durante sua manipulação. $O$ esgotamento das possibilidades de novidade implica a cessação das ações com o objeto (ELKONIN, 1998, p. 214).
}

Essa ideia deflagra a necessidade de um olhar atento do professor no sentido de observar a exploração das crianças, alternar os objetos do cesto e oferecer outros, quando necessário. A intervenção que realizamos contribuiu ainda, para refletirmos sobre a relação da professora com a criança pequena, ressaltando a importância dos adultos na formação de novas aprendizagens e capacidades. São os adultos que, ao participarem da vida dos bebês, poderão qualificar seu modo de exploração dos objetos, por duas vias: pela disponibilização intencional e planejada dos próprios materiais que integram o cesto e por meio da ampliação da linguagem das crianças, o que, como destacamos anteriormente, acarretará uma reorganização em seus processos psíquicos.

Os pressupostos da Psicologia Histórico-Cultural apontam que precisamos superar práticas calcadas no imediatismo, espontaneísmo e improviso que ainda se entrecruzem no trabalho educativo com os bebês, mirando para uma proposta de trabalho que seja representativa das inter-relações criança-mundo, mediadas pelo professor. $\mathrm{O}$ cesto dos tesouros é uma possibilidade potencial, já que, por meio desse recurso, é possível produzir transformações qualitativas no desenvolvimento da criança, instigando a curiosidade, o interesse e despertando o gosto pela cultura nas crianças, possibilitando 
compreensão mais aprimorada do mundo. Como assevera Saviani (2012, p. 73), precisamos ter em mente que

\begin{abstract}
A criança, desde a mais tenra idade, apresenta-se disposta a explorar o seu meio e, disponível a tudo o que a coloque como parte dele, responde prontamente a todos os estímulos. Assim, as atividades que lhe mostram diferentes sons, imagens, movimentos, odores, impressões táteis, as palavras que the são ditas, o sorriso, o afeto, a higiene, a alimentação - tudo is so, conjugado - constituem um amplo e profundo process o, o de apresentar à criança o mundo humano, ajudá-la a nele agir/interagir e, assim, torná-la humana. Tal processo, tornandose cada vez mais complexo, permite a apropriação, progressiva, dos múltiplos elementos culturais, contando, para isso, com a disposição e a disponibilidade da própria criança. Tudo ela quer ver, ouvir, pegar, falar, fazer, saber. E gosta de ter acesso a tudo, alegra-se com o mundo que vai descobrindo... No entanto, somente o consegue na interação, na comunicação com os indivíduos mais experientes.
\end{abstract}

E sem dúvida, nas instituições de Educação Infantil, esse adulto mais experiente é o professor, o profissional capaz de planejar, pesquisar, organizar o espaço, promover o encontro da criança com a cultura e desse modo, contribuir significativamente com o seu desenvolvimento.

\title{
REFERÊNCIAS BIBLIOGRÁFICAS
}

BARBOSA, M. C. S. Por amor \& por força: rotinas na educação infantil. 2000. 283 f. Tese (Doutorado em Educação) - Universidade Estadual de Campinas, Campinas, 2000.

BRASIL, Ministério da Educação. Secretaria de Educação Básica. Brinquedos, brincadeiras e materiais para bebês: manual de orientação pedagógica: módulo 2 . Brasilia: MEC/SEB, 2012.

ELKONIN, D. B. Desarrollo psíquico del niño desde el nacimiento hasta el ingreso en la escuela. In. SMIRNOV, A. A. et al. Psicología. México: Grijalbo, 1969b. p. 504522.

ELKONIN, D. B. Psicologia do jogo. São Paulo: Martins Fontes, 1998.

GOLDSCHMIED E; JACHSON, S. Educação de zero a três anos: o atendimento em creche. 2ed. Porto Alegre: Artmed, 2006.

LAZARETTI, L. M. A organização didática do ensino na educação infantil: implicações da teoria histórico-cultural. 204f. Tese (Doutorado em Educação) Universidade Federal de São Carlos, 2013. 
LEONTIEV, A. N. Las necesidades y los motivos de la actividad. In: SMIRNOV, A. A. et al. Psicología. México: Grijalbo, 1969. p. 341-354.

LIMA, E. A.; VALIENGO, A e RIBEIRO, A. E. M. Teoria Histórico-Cultural e o deesnvolvimento da percepção: fundamentos para a educação de bebês. Revista Teoria e Prática da Educação, v. 17, n.3, p. 25-36, Setembro/Dezembro 2014.

LÍSINA, M. La genesis de las formas de comunicación en los niños. In: DAVIDOV, V.; SHUARE, M. La psicologia evolutiva y pedagogia enla URSS. (Antologia). Moscou: Editorial Progresso, 1987. p. 59-67.

MARTINS, L. M. O ensino e o desenvolvimento da criança de zero a três anos. In: ARCE, A. e MARTINS, L. M. Ensinando aos pequenos de zero a três anos.

Campinas, SP: Alínea, 2009. p. 93 a 122.

MAJEM T; ÒDENA P. Descobrir brincando. Tradução: Suely Amaral Mello e Maria Carmem Silveira Barbosa. Revisão técnica: Ana Lúcia Goulart de Faria. Campinas, São Paulo, Autores Associados, 2010.

MUKHINA, V. Psicologia da idade pré-escolar. Tradução de Claudia Berliner. São Paulo: Martins Fontes, 1996.

MÚJINA, V. S. Características Psicológicas del prepreescolar y del preescolar. In. PETROVSKI, A. V. (Org.). La psicología evolutiva y pedagógica. Moscú: Progreso, 1979. p. 44-79.

MESQUITA, A. M. de. PASQUALINI, J. C. Desenvolvimento Infantil: Uma introdução à escola de Vigotski e suas implicações para o ensino da Educação Infantil. Unesp - Bauru, 2008. Mimeo.

SAVIANI, N. Educação infantil versus educação escolar: implicações curriculares de uma (falsa) oposição. In: ARCE, Alessandra; JACOMELI, Mara Regina Martins (Orgs.). Educação infantil versus educação escolar?: entre a (des)valorização e a precarização do trabalho pedagógico nas salas de aula. Campinas: Autores Associados, 2012.

VENGUER L. A. Temas de psicologia Preescolar. Havana: Pueblo y Educación: 1976.

VYGOTSKI, L. S.; LURIA, A. R. El instrumento y el signo en el desarrollo del niño. Tradução de Pablo del Río. San Sebastián de los Reyes Madrid: Fundación Infancia y Aprendizaje, 2007.

Recebido em: 01/06/2016

Aprovado em: 12/03/2017 